
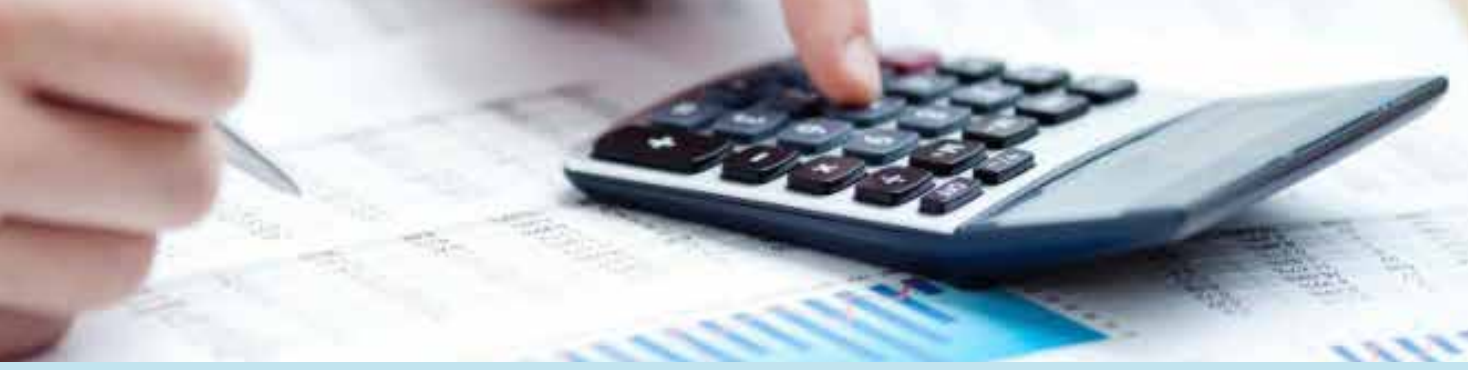

\title{
CONTROLE INTERNO NA ADMINISTRAÇÃO PÚBLICA: O CASO DA ASSESSORIA DE CONTROLE FINANCEIRO DA PAGADORIA DE PESSOAL DAMARINHA
}

\begin{abstract}
Artur Olavo Ferreira
Capitão de Mar e Guerra (IM). Estagiário do Curso de Altos Estudos de Política e Estratégia (CAEPE) da Escola Superior de Guerra. Mestre em Contabilidade (UER)). E-mail: arturolavo68@gmail.com Marcio Pinheiro de Vasconcellos

Capitão de Mar e Guerra (RM1-IM). Assessor de Controle Financeiro da Pagadoria de Pessoal da Marinha. Mestre em Economia Empresarial (UCAM).E-mail: vasconcellos@papem.mar.mil.br
\end{abstract}

\section{RESUMO}

Este artigo tem por objetivo apresentar o trabalho desenvolvido pela PAPEM, no tocante às boas práticas adotadas para aperfeiçoar e fortalecer o controle financeiro dos recursos gerenciados para a gestão do pagamento do pessoal da Marinha. Nesse sentido, aborda as atribuições conferidas à Assessoria de Controle Financeiro, idealizada especificamente para esse fim, cujo enfoque é o SISPAG2, fruto da modernização do Sistema de Pagamento da Marinha. As práticas ora adotadas mostram-se alinhadas aos objetivos da Controladoria-Geral da União, Órgão do Governo Federal, que, dentre outras prerrogativas, é responsável pela defesa do patrimônio público e do incremento da transparência da gestão, por meio das atividades de controle interno. Isto posto, o que se espera, em última instância, é a eficaz gestão dos recursos públicos, em especial dos recursos próprios de pagamento de pessoal, com a transparência que the é devida.

Palavras-chave: Controle Financeiro; Gestão de Pagamento; SISPAG2; Transparência; Controle Interno.

\section{ABSTRACT}

This article aims to present the work of the PAPEM, with regard to good practices to improve and strengthen the financial control of managed resources for the management of Brazilian Navy personnel payment. In this sense, it deals with the powers conferred to the Financial Control Advisory, created specifically for this purpose, whose focus is the SISPAG2, due to the modernization of the Brazilian Navy's Payment System. The practice now adopted prove to be aligned with the goals of Comptroller General of the Union, organ of the Federal Government, which, among other prerogatives, is responsible for defending the public patrimony and increase the transparency of management through internal control activities. That said, what is expected, ultimately, it is the effective management of public resources, especially of own resources for personal payment, to transparency due to it.

Keywords: Financial control; Payment management; SISPAG2; Transparency; Internal control. 


\section{INTRODUÇÃO}

A Pagadoria de Pessoal da Marinha (PAPEM) adota, há vários anos, práticas graduais, que promovem o fortalecimento do controle interno nos assuntos que the são afetos. Atua no viés do controle financeiro, com práticas gerenciais alinhadas aos objetivos da Controladoria-Geral da União, que é o órgão do Governo Federal responsável por assistir direta e imediatamente ao Presidente da República quanto aos assuntos que, no âmbito do Poder Executivo, sejam relativos à defesa do patrimônio público e ao incremento da transparência da gestão, por meio das atividades de controle interno, auditoria pública, correição, prevenção e combate à corrupção e ouvidoria (CONTROLADORIA-GERAL DA UNIÃO, 2015).

Nesse contexto, foi criada em abril de 2015 uma Assessoria própria para essa atividade, que vem desenvolvendo aperfeiçoamentos, para melhor atingir os propósitos de uma gestão eficaz dos recursos destinados ao pagamento de pessoal.

Neste artigo, serão abordadas as atribuições da Assessoria de Controle Financeiro, em seus pormenores, sem deixar de ressaltar o Sistema de Pagamento em implantação, o SISPAG2, que proporcionará maiores facilidades de controle, em virtude da implantação das medidas adicionais para esse fim. Para tal, o estudo encontra-se dividido nas seguintes seções: Introdução; A PAPEM e o Controle Financeiro; Controle sobre a base de dados do Pagamento de Pessoal; Outras Atribuições do Controle Financeiro; e Considerações Finais.

\section{A PAPEM E O CONTROLE FINANCEIRO}

A PAPEM é a Organização Militar (OM) da Marinha do Brasil (MB) responsável pela administração dos sistemas de pagamento atinentes ao pessoal da Marinha, no país e no exterior, com a finalidade de contribuir com a eficácia do preparo e da aplicação do Poder Naval.

Nesse escopo, executa o pagamento aproximadamente de 200.000 pessoas entre militares, servidores civis, beneficiários de pensões militares, ex-combatentes, anistiados políticos, além de beneficiários de anistiados políticos.

Na consecução de suas tarefas, a OM dispõe de três Departamentos ligados à atividade-fim, que são: Departamento de Sistemas de Pagamento, Departamento de Finanças e Departamento de Consignações. Para o cum- primento da atividade-meio, conta com o Departamento de Informática e o de Administração.

Com o propósito de melhorar a atividade de controle financeiro, bem como otimizar a fiscalização das tarefas atinentes ao Sistema de Pagamento de Pessoal (SISPAG2)' e à distribuição de recursos conotados aos gastos de pessoal da MB, foi criada, em $1^{\circ}$ de abril de 2015 , e ainda sendo regulamentada, a Assessoria de Controle Financeiro (PAPEM-09), subordinada diretamente ao Diretor, que, dentre outras, possui as seguintes atribuições: 1) atuar junto ao Centro de Análise e Sistemas Navais $\left(\right.$ CASNAV) ${ }^{2}$ para automatização das atividades de controladoria do SISPAG2; 2) efetuar o controle interno sobre a atividade de pagamento de pessoal, enfatizando o procedimento de crítica sobre as alterações mensais de pagamento; 3) avaliar, comparativamente, as Organizações Militares Centralizadoras de Pagamento (OC), no que tange a comportamentos esperados de parcelas de pagamento; 4) implementar mecanismos de controle e acompanhamento dos valores não repassados do MANUFAL 3 ; 5) implementar mecanismos de controle e acompanhamento dos valores repassados às Entidades Consignatárias4; 6) implementar outros mecanismos de controle e acompanhamento, à luz dos processos de desembolso existentes na PAPEM, ou determinados pelo Diretor, em especial os que afetem o saldo das contas de passivo; e 7) atuar junto ao Serviço de Inativos e Pensionistas da Marinha (SIPM), visando contribuir para o aumento da capacidade de controle daquele Serviço, referente aos processos de pagamento de inativos e pensionistas.

Essa Assessoria, com o desenvolvimento de suas atribuições, visa criar soluções fáceis para os problemas inerentes ao controle financeiro, e, por conseguinte, para o controle interno do sistema de pagamento, levando em consideração:

\footnotetext{
Sistema informatizado de pagamento da Marinha desenvolvido para realizar o pagamento de todo o pessoal militar ativo e inativo, bem como os pensionistas instituídos. 0 sistema passou por uma fase de aperfeiçoamento, tendo sido desenvolvido e implantado o SISPAG2 em agosto de 2016.

2 Organização Militar cujamissãoécontribuir para o Desenvolvimento Tecnológico da Marinha e do País.

3 Parcelas atinentes à Pensão Alimentícia instituída por via judicial.

4 Pessoa de direito público ou privado em favor da qual a Marinha, mediante instrumento administrativo, poderá autorizar descontos na remuneração do pessoal que mantém relação e vínculo de remuneração com a Marinha, por meio do SISPAG2.
} 
○ a utilização de ferramentas gerenciais que apresentem baixo custo de implantação;

○ não haver acréscimo de carga burocrática desnecessária;

- a geração de efeitos positivos, a ponto de servir de benchmarking a outros órgãos públicos; e
- ser de fácil replicabilidade.

Na Figura abaixo, é apresentado o organograma que contempla a estrutura administrativa da PAPEM, onde se pode observar a localização hierárquica da Assessoria de Controle Financeiro:

Figura 1: Organograma da Pagadoria do Pessoal da Marinha

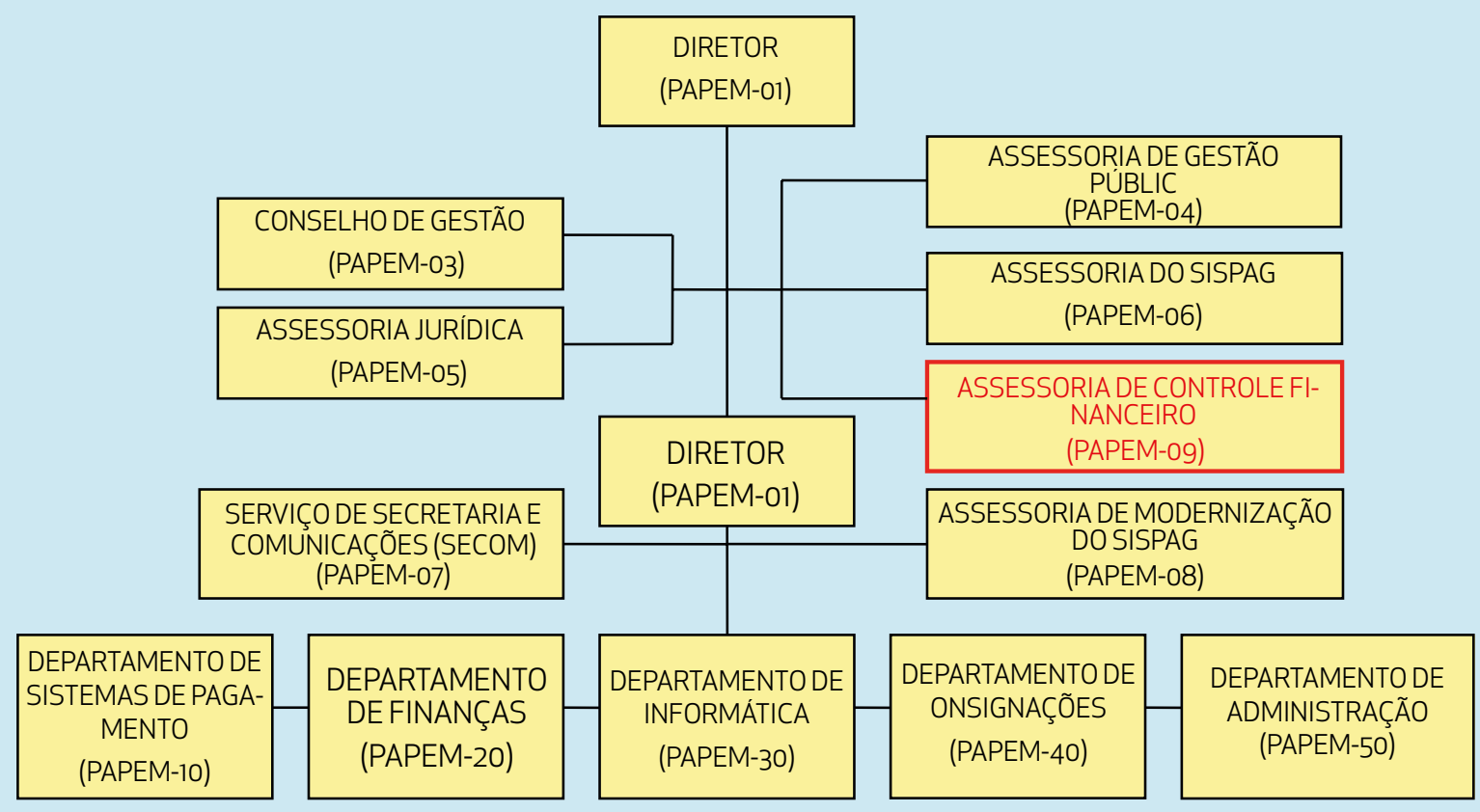

口 Fonte: Regimento Interno da PAPEM de 2016

As atribuições da Assessoria de Controle Financeiro são perfeitamente caracterizadas pelo aspecto da controladoria, que, por sua vez, exerce, atualmente, um papel fundamental para as grandes organizações, tanto pela competitividade inerente aos mercados atuais, que exige o uso eficaz de seus recursos, como pela racionalização destes, evitando-se desperdícios de toda ordem. Assim, nada melhor que controlar os processos para se ter uma organização realmente capaz de se tornar competitiva na sua área de atuação.

Para Lunelli (2015), a controladoria possui uma importância elevada:

As empresas modernas e que se preocupam com um processo de gestão bem desenvolvido, necessitam de uma estrutura organizacional bem delineada para a sua sobrevivência. Neste novo cenário surge um órgão interno cuja finalidade é garantir que as informações sejam adequadas ao processo decisório e que esteja sempre pronta a apoiar a diretoria da entidade no processo de gestão. É claro que estamos falando da controladoria!

\section{CONTROLE SOBRE A BASE DE DADOS DO PAGAMENTO DE PESSOAL}

A atuação do controle sobre o pagamento de pessoal justifica-se pela grandeza dos valores envolvidos. Con- 
forme realçou o ex-ministro da Controladoria Geral da União5, os volumes de recursos envolvidos no gasto de pessoal justificam incremento do controle, como processo de aprimoramento de gestão.

Ainda sobre os aspectos de controle que envolvem a folha de pagamento da PAPEM, é interessante destacar o que foi apresentado por Leal e Silva (2013), ao detaIharem os principais vetores de controle utilizados na Pagadoria:

- Depuração da Folha País - verificação efetuada pelo SISPAG sobre as alterações (inclusão/exclusão/alteração de parcela) de pagamento enviadas mensalmente pelas $\mathrm{OC} / \mathrm{IQ}$ a que se dá o nome de "depuração" do pagamento;

- Controladoria da Folha País - em complemento às atividades de Depuração, tem como objetivo principal o acompanhamento da execução dos atos, identificando, em caráter opinativo, preventivo ou corretivo, se as ações desempenhadas estão de acordo com a legislação; e

- Controladoria da Folha Exterior - com o foco de verificar inconsistências no pagamento de militares designados para missões transitórias e permanentes no exterior.

\section{3.1 Situação atual da Assessoria de Controle Financeiro}

Até o ano de 2015, o controle financeiro era realizado com poucos recursos sistêmicos. Desta forma, para viabilizar algumas consultas diretas ao banco de dados de pagamento (CGS), relativas às possiveis discrepâncias no processo mensal, foi fundamental a parceria com o CASNAV, no intuito de se automatizar essas consultas (queries), que são geradas na linguagem Structured Query Language (SQL) 6 .

Isto posto, em dezembro desse mesmo ano, foi ativado,

5 Disponivel em: <http://www.cgu.gov.br/noticias/2016/02/ controladoria-geral-da-uniao-apresenta-nova-carga-do-sistemade-trilhas-de-auditoria.> Acesso em: 07 mai.2016.

6 Structured Query Language, ou Linguagem de Consulta Estruturada ou SQL, é a linguagem de pesquisa declarativa padrão para banco de dados relacional (base de dados relacional). Muitas das características originais do SQL foram inspiradas na álgebra relacional. Alves (2009) atribui a criação da SQL ao artigo de Edgard F. Codd, um pesquisador da IBM, intitulado "A Relational Modelo of Data for Large Shared Databanks", que foi publicado em junho de 1970 com êxito, o módulo de controladoria do SISPAG2, que passou a abarcar essas automatizações, conforme será tratado mais adiante, permitindo que alguns resultados possam ser verificados in loco.

Para fins de apresentação das "boas práticas"7 adotadas pela PAPEM, serão detalhadas as atribuições da Assessoria de Controle Financeiro, citadas no item 2, enfatizando-se, inicialmente, as três primeiras.

Para uma melhor compreensão, passa-se a descrever o processo das consultas de forma generalizada. 0 processo de pagamento do pessoal militar é composto de diversas etapas, que vai desde a captação das alterações mensais enviadas pelas $\mathrm{OC}$ até o efetivo crédito em conta-corrente no dia do pagamento, realizado junto aos bancos conveniados. No decorrer desse processo, algumas discrepâncias podem ocorrer, seja por erro do próprio sistema, ao apresentar inconsistência, ou pela digitação equivocada realizada por algum Agente de Pagamento. Sendo assim, esses erros acabam por prejudicar o fluxo financeiro destinado ao pagamento de pessoal.

Após o processamento das alterações mensais, é gerado um banco de dados, o Cadastro Geral de Servidores (CGS), que contém informações relativas à folha de pagamento do mês atual. A partir desse banco, a Assessoria de Controle Financeiro promove diversas consultas (queries), previamente definidas, a fim de buscar as possiveis discrepâncias existentes.

Essas consultas são escritas em linguagem SQL e, ao serem executadas, apresentam os resultados, de acordo com os parâmetros delineados. Os parâmetros são definidos, levando-se em consideração os erros mais comuns observados pela PAPEM. Atualmente, existem mais de 30 consultas, rodadas mensal ou quadrimestralmente, de acordo com o grau de criticidade que the é atribuido. Após terem sido empreendidas todas as queries em um determinado mês, são transmitidas mensagens administrativas às OC, informando as discrepâncias verificadas, a fim de que possam solucioná-las tempestivamente.

O uso dessa facilidade tecnológica coaduna com o princípio de controle interno de "utilizar o máximo possível de recursos computacionais, com procedimentos internos e sequenciais".(PADOVEZE, 2003, p.38). Cabe ressaltar que

\footnotetext{
Boas práticas significam um conjunto de ações direcionadas, que visam proporcionar uma gestão eficaz, que gerem os resultados esperados.
} 
a PAPEM não é a Organização Militar responsável pela atividade de controle interno da Marinha, entretanto, ela realiza o controle sobre o banco de dados, gerado mensalmente, relativo ao pagamento de pessoal. $O$ intuito é facilitar o trabalho de controle interno das OC, por meio desta ferramenta, auxiliando nas conferências previstas nas Normas.

Para as consultas com alto grau de criticidade, as mensagens transmitidas exigem resposta com prazo estipulado, contendo as ações em andamento para a solução do problema. De posse da quantidade de discrepâncias apresentadas, a PAPEM pode identificar as OC que apresentam o maior número de erros, e a atuar pontualmente, voltando sua atenção à descoberta das razões dessas OC terem cometido a maior quantidade de erros ao longo do período analisado.
Por exemplo, muitas vezes, descobre-se que o pessoal empregado para a gestão de pagamento, em uma determinada OC, é inexperiente, precisando de orientações mais direcionadas, ou até mesmo existe um acúmulo de funções para o pessoal que trabalha nessa gestão, tornando-a pouco eficiente.

Por outro lado, permite à PAPEM orientar quanto ao uso operacional correto do sistema informatizado de pagamento, bem como evitar que as discrepâncias voltem a ocorrer, pelo menos para essa OC em especial. Quando necessário e pertinente, são divulgadas orientações gerais em documento próprio da MB, o Boletim de Ordens e Notícias (BONO), a fim de dar publicidade às soluções para os erros mais recorrentes, bem como os procedimentos adequados para o devido acerto. Visualizam-se no quadro abaixo exemplos de consultas executadas atualmente.

Quadro 1: Principais queries realizadas



Fonte: Elaborada pelos autores 
Como se pode observar, o objetivo dessa gama de consultas ao banco de dados do pagamento mensal, o CGS, é evitar e/ou corrigir, em tempo, as irregularidades de pagamento, gerando, como consequência, o adequado uso dos recursos públicos, o que vem a corroborar com a ideia da defesa do patrimônio público e do incremento da transparência da gestão, por meio das atividades de controle interno.

Resta salientar que as consultas mencionadas, atualmente, são executadas por intermédio do Módulo de Controladoria do SISPAG2. Esse módulo possibilita que as OC, por meio dos Agentes de Pagamento, possam visualizar e igualmente executar as verificações das possíveis discrepâncias diretamente no computador, devendo, portanto, tomar atitudes imediatas para saná-las com a maior brevidade, agregando celeridade ao processo.

É importante frisar que a tarefa de efetuar consultas parametrizadas ao CGS tem um caráter cíclico e dinâmico, ou seja, além de alimentar a PAPEM constantemente acerca das discrepâncias existentes, pode e deve ser aperfeiçoada ao longo do tempo. Todavia, o número de discrepâncias jamais atingirá o nível zero, tendo em vista que o processo mensal de pagamento é repleto de variáveis exógenas, e sendo assim, erros que já haviam sido aparentemente estancados em um processo, poderão vir a ocorrer em outros, mesmo com as precauções adotadas.

\section{3.20 SISPAG2}

A diversidade de consultas executadas mensal, trimestral ou quadrimestralmente, como já mencionado, tem como base o banco de dados gerado pelo sistema informatizado de pagamento, que vem sendo modernizado de forma a torná-lo mais ágil, confiável, eficaz e de fácil interação com os Agentes de Pagamento, possibilitando à Marinha maior capacidade de gestão dos recursos públicos destinados à Folha de Pagamento.

Um grande avanço no aspecto do controle é o SISPAG2. Cabe destacar que as atividades de controle permitiram o acúmulo de conhecimento que deu base para a definição de diversas regras de negócio desse novo Sistema. A implantação do novo Sistema foi realizada de forma prudente e gradual, para os inativos e pensionistas em outubro de 2014, e, a partir do mês de agosto de 2016, para todo o pessoal da Ativa.

Da mesma forma, busca-se uma maior integração com o Sistema de Inativos e Pensionistas da Marinha (SIPEM), o que permitirá o incremento no nível de controle interno da gestão do pagamento de inativos e pensionistas, bem como dar uma ênfase maior para o controle financeiro para os Militares da Ativa. Esse é o papel que a controladoria exerce, em especial, na PAPEM (QUADRA; FERREIRA, 2015).

Como características principais do SISPAG2, podem ser citadas as seguintes: 1) Operação no País (Real) e no Exterior (Dólares Americanos / Euro / Libra); 2) Agilidade operacional decorrente da Centralização do processamento na PAPEM, bem como Descentralização de informações, haja vista a existência de 113 Organizações Centralizadoras (OC), 22 Informantes Qualificados no âmbito da Marinha (IQ-MB) e 78 Informantes Qualificados extra Marinha (IQ-EX), correspondentes às Entidades Consignatárias; 3 ) Prestação de Contas em diversos níveis; 4) Fiscalizações intercorrentes; e 5) Grande número de relacionamentos com outros sistemas e entidades.

Para Ferreira (2015), a modernização do SISPAG deu-se por conta de diversos fatores motivadores, dentre os quais, os principais são: 1) Necessidade de integração com os sistemas de gestão de pessoal da MB; 2) Limitada utilização do ambiente web;3) Obsolescência tecnológica relacionada à linguagem COBOL; 4) Dificuldade crescente na manutenção evolutiva, devido à falta de documentação das Regras de Negócio; e 5) Razão custo-benefício da plataforma Mainframe desfavorável.

Segundo Ferreira (2013), esse projeto foi concebido sob as modernas técnicas de tecnologia da informação, visando serem suplantadas as deficiências identificadas no sistema anterior, como, por exemplo: a limitada capacidade de desenvolvimento de novas funcionalidades; a escassa documentação do software; a pouca viabilidade técnica de implementar adequadas rotinas de controle; a baixa capacidade de implementar críticas automatizadas e a dificuldade para o fornecimento de informações para o Banco de Informações Estratégicas e Gerenciais (BIEG) do Ministério da Defesa.

Com a modernização em andamento, abriu-se o adequado espaço para a maior exploração do viés da controladoria, tendo em vista que um dos benefícios esperados é a implementação de medidas adicionais de controle interno, e para isso, novas funcionalidades estão sendo desenvolvidas e implantadas.

Dessa forma, haverá um incremento no controle interno da folha de pagamento da Marinha, pois, muitos dos erros 
hoje constatados após o processamento da folha serão impedidos de acontecer, ou seja, nesta situação o controle passará a ser exercido "ex-ante".8

A título de apresentação dos benefícios advindos do SISPAG2, independente de um módulo próprio de controladoria, pode-se demonstrar pelo Quadro 1 abaixo, uma análise comparativa das principais constatações observadas nos processos de pagamento mensais, e o impacto do novo sistema sobre estas:

\section{Quadro 2: Principais constatações observadas nos processos de pagamento mensal}

\begin{tabular}{|c|c|c|c|c|}
\hline \multirow{2}{*}{$\begin{array}{l}\text { DESCRIÇÃO } \\
\text { DAS PRINCIPAIS } \\
\text { CONSTATAÇÕES }\end{array}$} & \multicolumn{4}{|c|}{ OCORRÊNCIAS } \\
\hline & 2012 & 2013 & 2014 & 2015 \\
\hline $\begin{array}{l}\text { AUXÍLIO-TRANSPORTE } \\
(*)\end{array}$ & 479 & 566 & 453 & 464 \\
\hline ACERTO DE CONTAS & 78 & 138 & 98 & 93 \\
\hline $\begin{array}{l}\text { ADICIONAL MILITAR } \\
\text { (Percentual incorreto) (*) }\end{array}$ & 378 & 418 & 799 & 817 \\
\hline $\begin{array}{c}\text { ASSISTÊNCIA } \\
\text { PRÉ-ESCOLAR (*) }\end{array}$ & 119 & 118 & 102 & 58 \\
\hline $\begin{array}{l}\text { ATIVO NA OC } 930 \text { (SIPM) } \\
\text { E INATIVOS FORA DA OC } \\
930\left(^{* *}\right)\end{array}$ & 82 & 119 & 46 & 0 \\
\hline $\begin{array}{l}\text { CONTA-CORRENTE / CPF } \\
\text { EM DUPLICIDADE }\end{array}$ & 88 & 25 & 94 & 34 \\
\hline $\begin{array}{c}\text { FUSMA (Não implantada a } \\
\text { parcela) (*) }\end{array}$ & 1.283 & 1.452 & 421 & 947 \\
\hline PENSÃO MILITAR & 667 & 195 & 220 & 533 \\
\hline $\begin{array}{c}\text { REATIVAÇÃO DE } \\
\text { PAGAMENTO (suspenso/ } \\
\text { bloq. no mês anterior) }\end{array}$ & 608 & 273 & 302 & 323 \\
\hline $\begin{array}{l}\text { RECEBIMENTO } \\
\text { DE PARCELASEM } \\
\text { DUPLICIDADE }\end{array}$ & 1.332 & 844 & 725 & 1708 \\
\hline TOTAL & 5.119 & 4.148 & 3.260 & 4977 \\
\hline
\end{tabular}

Fonte: Apresentação do SISPAG2 no Comando do $3^{\circ}$ Distrito Naval em junho de 2015.

8 Cruz Silva (1999, apud DAVIS E BLASCHEK, 2006) aduz que no controle ex-ante, as ações de controle e avaliação acontecem antes da ocorrência do evento ou fato que se pretende controlar, com o intuito de prevenir ou impedir o sucesso de atos indesejáveis como erros, desperdícios ou irregularidades.
De acordo com Ferreira (2015), com a instalação do SISPAG2, espera-se que seja evitado $50 \%$ do total das constatações acima, sendo eliminadas aquelas destacadas com asterisco.

\section{OUTRAS ATRIBUIÇÕES DA ASSESSORIA DE CONTROLE FINANCEIRO}

Conforme citado anteriormente, outras atribuições são conferidas à Assessoria de Controle Financeiro da PAPEM, especialmente as seguintes:

1) Implementação de mecanismos de controle e acompanhamento dos valores (consignações) não repassados do MANUFAL:

Mensalmente, por meio de um módulo de Repasse de Benefícios (RBEN), são identificados todos os repasses, por tipo de benefício, seja Pensão Alimentícia, Aluguel de Imóvel, Benefício Família, além dos Descontos Judiciais. Dessa forma, é possível levantar o total dos valores pendentes, ou seja, que deixaram de ser repassados por qualquer tipo de inconsistência (erro de conta-corrente, beneficiário não identificado entre outros). Esses valores, além de identificados no Relatório Resumo Financeiro do RBEN, passaram também a ser confrontados com os valores registrados no SIAFI, visando dar maior transparência e controle financeiro e contábil.

2) Implementação de mecanismos de controle e acompanhamento dos valores repassados às Entidades Consignatárias (EC):

Com relação às consignações, foi criado um Relatório Especial de Acompanhamento e Controle, que visa identificar, por Entidade Consignatária, as diferenças de valores descontados dos Militares/Pensionistas. Assim, é possível saber o valor descontado a maior ou a menor, bem como a incidência dessa ocorrência. Essa prática visa evitar os erros de descontos, que venham a prejudicar os Militares, e também, apresentar às Entidades Consignatárias os casos inversos.

No entanto, é clarividente que, muitas vezes, o pessoal descontado a maior não percebe o erro, às vezes, por ser pequeno o valor ou por descuido de gestão particular, causando um dano grande ao haver uma incidência elevada de descontos errados para a mesma pessoa. Para os casos porventura existentes, a Entidade Consignatária é notificada para, em um prazo definido, efetuar a restituição dos valores descontados erroneamente. Além disso, 
o próprio programa já permite o acerto para valores de descontos alterados por términos ou alterações contratuais, reduzindo mais uma preocupação por parte do Gestor da PAPEM.

3) Implementação de outros mecanismos de controle e acompanhamento, à luz dos processos de desembolso existentes na PAPEM, ou determinados pelo Diretor, em especial os que afetem o saldo das contas de passivo:

As contas de passivo devem ser controladas e acompanhadas de forma efetiva e sistêmica. Assim, especialmente em relação à conta Depósito de Terceiros, foram criadas várias contas correntes, a fim de se identificar corretamente os valores creditados ao longo do mês, por meio das Guias de Recolhimento da União (GRU). Após a identificação, os valores são destinados para os fins específicos correspondentes, mantendo na conta os valores perfeitamente identificados.

Essa prática possibilita a transparência pública necessária para uma boa gestão de recursos financeiros, mais uma vez, fortalecendo o processo de controle interno.

4) Atuação junto ao SIPM, visando contribuir para o aumento da capacidade de controle daquele Serviço, referente aos processos de pagamento de inativos e pensionistas:

Levando em consideração que o SIPM possui um total aproximado de 110.000 militares inativos e pensionistas, é natural que haja um relacionamento próximo entre a PAPEM e aquela OM. Desta forma, foram realizados alguns encontros, a fim de se traçar alguns procedimentos com o intuito de contribuir para o controle financeiro dos processos de pagamento específicos para esse pessoal. Como ação decorrente, foram elaboradas consultas ao banco de dados do CGS, solicitadas pelo próprio SIPM.

Essas consultas são visualizadas somente pela PAPEM, SIPM e CCIMAR (Órgão de Controle Interno da Marinha), o qual possui perfil para visualizar todas as consultas disponíveis no módulo, independente da OC/OM.

Todavia, mensalmente, e em paralelo, a Assessoria de Controle Financeiro realiza essas consultas específicas e as encaminha ao Departamento de Controle Interno daquela $\mathrm{OM}$, para que seja dado o tratamento adequado. Dessa forma, o trabalho ora realizado contribui com o controle do SIPM, permitindo, também, mais uma vez, o fortalecimento do controle interno no que tange ao pagamento de pessoal.

\section{CONSIDERAÇÕES FINAIS}

O objetivo do presente artigo foi apresentar práticas adotadas pela PAPEM para o aperfeiçoamento do controle interno nos assuntos que lhe são afetos. Nesse contexto, é possível observar que as ações já em curso, por essa $\mathrm{OM}$, condizem exatamente com os objetivos da Controladoria-Geral da União (CGU).

A criação da Assessoria de Controle Financeiro da PAPEM, em $1^{\circ}$ de abril de 2015 , teve o propósito de melhorar o controle financeiro, bem como otimizar a fiscalização das tarefas atinentes ao Sistema de Pagamento de Pessoal e à distribuição de recursos conotados como gastos de pessoal. Os frutos esperados para um curto prazo são, em última instância, a boa gestão dos recursos públicos com a transparência que lhe é devida, e, por conseguinte, a sua racionalização.

Conforme discutido no texto, até o ano de 2015, o controle financeiro era realizado com poucos recursos sistêmicos, o que acarretava o dispêndio de tempo elevado e, concorrendo com as inúmeras tarefas da OM, acabava por ficar relegado ao segundo plano. A criação da Assessoria de Controle Financeiro permitiu a existência de um elemento organizacional exclusivamente dedicado às tarefas existentes e ao incremento do controle.

De modo a agilizar e facilitar algumas consultas relativas a possíveis discrepâncias de pagamento buscou-se uma parceria com o CASNAV, no intuito de se realizar a automatização dessas consultas. As queries, como são denominadas as consultas, são geradas à linguagem Structured Query Language (SQL) e se destinam a pesquisar o banco de dados após o recebimento de todas as alterações mensais de pagamento, enviadas pelas Organizações Militares Centralizadoras (OC) e já depuradas pelo Departamento de Sistemas de Pagamento.

Com a ativação do módulo de controladoria do SISPAG2, muitos resultados passaram a ser verificados in loco, propiciando, assim, uma racionalização e fortalecimento do controle interno das OM. Com o advento das práticas, ora em andamento, já se pode perceber a quantidade de correções que são possíveis em um curto espaço de tempo.

É imperioso reafirmar que o trabalho da controladoria exige seriedade, constância e, acima de tudo, um acompanhamento que agregue valor ao trabalho final e não seja uma barreira no sentido de prejudicar o trabalho como um todo. Ou seja, o controle precisa e deve existir para ajudar 
a melhor gerir os recursos e não para impedir ou dificultar a gestão.

Em última análise, espera-se que o presente estudo possa contribuir para os desígnios da Marinha do Brasil, especialmente no que se refere ao alinhamento de objetivos com a Controladoria-Geral da União.

\section{REFERÊNCIAS}

ALVES, William Pereira. Banco de dados: teoria e desenvolvimento. São Paulo: Érica, 2009.

CONTROLADORIA-GERAL DA UNIÃO. Institucional, 2015 Disponivel em: 〈http://www.cgu.gov.br/sobre/institucional〉 Acesso em: 31 ago. 2015.

DAVIS, Marcelo David; BLASCHEK, José Roberto de Souza. Deficiências dos sistemas de controle interno governamentais atuais em função da evolução da economia. In: Anais do Congresso USP de Controladoria e Contabilidade. 2006. Disponivel em: <http://cont.aedb.br/seget/artigos05/340_artigoSEGET.pdf>. Acesso em 26 jun.2016.

DIRETORIA DE COORDENAÇÃO DO ORÇAMENTO DA MARINHA. Regulamento interno da Pagadoria de Pessoal da Marinha, Brasília, 2013.

FERREIRA, Artur Olavo. Palestra realizada no Comando do $3^{\circ}$ Distrito Naval. 2015.

FERREIRA, Renato Cesar da Cunha. Projeto Sispag-2. Revista PAGMAR, Rio de Janeiro, v. 1, n. 1, p. 38-43, jan./dez. 2013.
LEAL, Rodrigo Barreiros; SILVA, Anderson Soares. Controladoria e Qualidade do gasto Público: O Caso da Pagadoria de Pessoal da Marinha do Brasil. Revista PAGMAR, Rio de Janeiro, v. 1, n. 1, p. 44-55, jan./dez. 2013.

LUNELLI, Reinaldo Luiz. A importância da controladoria. Portal de Contabilidade, 2015. Disponível em: < http://www.portaldecontabilidade.com.br/tematicas/importancia-controladoria. htm> Acesso em: 31 ago. 2015.

PADOVEZE, Clóvis Luis. Controladoria, Estratégica e Operacional. São Paulo: Thomsom Learning, 2003.

PAGADORIA DE PESSOAL DA MARINHA. Regimento Interno, Rio de Janeiro, 2014.

PAGADORIA DE PESSOAL DA MARINHA. SISPAG2: Software. Versão 2015. Rio de Janeiro, 2015.

QUADRA, Leo Fernandes; FERREIRA, Renato Cesar da Cunha. SISPAG 2. Revista PAGMAR, Rio de Janeiro, nº 03, 2015.

SECRETARIA-GERAL DA MARINHA. Normas sobre Pagamento de Pessoal. SGM-302. 5ª Revisão. Brasília, 2015.

\section{Como citar este documento:}

FERREIRA, A. O.; VASCONCELLOS, M. P. de. Controle Interno na Administração Pública: O Caso da Assessoria de Controle Financeiro da Pagadoria de Pessoal da Marinha. Revista PAGMAR, Rio de Janeiro, v. 5, n. 5, p. 15 - 23, jan./dez. 2017.

Digital Object Identifier (DOI): http://dx.doi.org/10.4322/pagmar.2446-4791.2016.002

\section{Recebido em 01JUL2016. Última versão recebida em 05SET2016. Aprovado em 280UT2016.}

Avaliado pelo sistema Triple Review: a) Desk Review pelo Editor-Chefe; e b) Double Blind Review (avaliação cega por dois avaliadores da área).

Revisão: Gramatical, Normativa e de Formatação.

\section{Crossef @ $\Theta \otimes$}

